Park, H., \& Lee, J. (2019). Discourse analysis of online product reviews: A discussion of digital consumerism and culture. Cyberpsychology: Journal of Psychosocial Research on Cyberspace, 13(2), article 4.

http://dx.doi.org/10.5817/CP2019-2-4

\title{
Discourse Analysis of Online Product Reviews: A Discussion of Digital Consumerism and Culture
}

\author{
Haseon Park ${ }^{1} \&$ Joonghwa Lee ${ }^{1}$ \\ ${ }^{1}$ Department of Communication, University of North Dakota, Grand Forks, ND, USA
}

\begin{abstract}
This study focuses on consumer interaction via online product reviews in digital markets by incorporating intercultural perspective. In doing so, this study explores the representation of digital consumerism, defined as development of consumer empowerment and vulnerability in digital markets, which appears as a paradigm to ensure balanced market environments for both consumers and companies (Kucuk, 2016). In particular, this study investigates cultural differences in the representation of digital consumerism in online product reviews by comparing the online product reviews from U.S. and South Korea. Additionally, message strategies employed in the online product reviews were also examined in respect of digital consumerism while comparing the two cultures. A discourse analysis on a total of 400 online product reviews (i.e., 200 from U.S., 200 from South Korea) was conducted to understand how digital consumerism can be constructed. The results indicated significant cultural differences between the U.S. and South Korea based on online consumer powers manifested in the content of online product reviews as well as message strategies adopted to express digital consumerism. In the U.S., economic, technologic, and social power were more frequently observed in online product reviews compared to legal power; In contrast, in South Korea, economic power was the most frequently observed, followed by social and technologic power. In terms of message strategies, transformational messages were dominantly used to express digital consumerism in online product reviews from both countries, whereas each type of online consumer powers was expressed differently in the U.S. and South Korea by adopting different message strategies. Theoretical and practical implications are discussed.
\end{abstract}

Keywords: Digital consumerism; culture; online product reviews; discourse analysis

\section{Introduction}

Consumers in digital marketplaces can easily access products from different countries (Shepard, 2017). The development of digital platforms, such as mobile devices and social networking sites (SNS), has made it easier for consumers to browse for products offered by companies across the globe and share their opinions through online product reviews, resulting in the increase in the number of consumers purchasing products, worldwide (IPC, 2016, 2017). Along with this trend, it has become essential for advertisers to understand the characteristics of consumers who have different cultural backgrounds in order to effectively promote their products to target consumers. Furthermore, from the consumers' perspective, the vulnerabilities they might be exposed to in digital markets, such as misinformation, should be considered to maintain and enhance consumer rights in terms of digital consumerism (Kucuk, 2016).

To protect consumers in competitive markets where consumers do not necessarily have appropriate information and tools to satisfy their needs, more attention should be paid to address the issue of consumer vulnerabilities in digital markets (Donoghue, Van Oordt, \& Strydom, 2016). Therefore, both consumers and companies should be 
equally empowered and balanced in market environments. Kucuk (2009) defined this well-balanced interaction between consumers and companies as market equalization, and noted that it enhances consumer empowerment. Consumers' exposure to vulnerabilities is minimized in a well-functioning market environment. The concept of digital consumerism, defined as the paradigm of consumer powers in digital markets, has been developed to deal with the power discrepancy that exists between consumers and companies in the process of online market interactions (Kucuk, 2016). Market equalization contributes to consumerism by allowing a balanced interaction between consumers and companies to reduce any harm to consumers (Kucuk, 2009, 2012, 2016). In digital markets, an online product review is one of the most convenient and accessible tools that consumers and companies can use to interact with each other. Thus, this study aims to better understand digital consumerism, as expressed in online product reviews, in order to explore the interactions between consumers and companies in digital markets.

Several studies have attempted to conceptualize consumer power in digital markets (Denegri-Knott, Zwick, \& Schroeder, 2006; Kerr, Mortimer, Dickinson, \& Waller, 2012; Kucuk, 2008; Labrecque, vor dem Esche, Mathwick, Novak, \& Hofacker, 2013; Zureik \& Mowshowitz, 2005). In particular, Kucuk (2009) explained four types of consumer power in the context of digital markets: technologic, economic, social, and legal powers. These consumer powers are observed in the form of product reviews in online advertising. For example, an online product review is one of the tools that online consumers use to protect their rights and claim social power. Online product reviews can include sharing information and opinions with other consumers for future purchases (Li, Huang, Tan, \& Wei, 2013).

Despite the abundance of research on online product reviews (King, Racherla, \& Bush, 2014; Lee \& Youn, 2009; Li et al., 2013; Siano, Vollero, \& Palazzo, 2011; Tirunillai \& Tellis, 2012), few studies have addressed the role of product reviews as a tool to represent digital consumerism. To fill this gap, the present study aims to explore how online consumers construct their opinions in online product reviews as a manifestation of digital consumerism and how such practices vary between cultures. Because online product reviews written by consumers could work as usergenerated advertisements in e-commerce websites affecting the purchase decision-making process of other consumers, similar to traditional advertising messages, it is essential to explore the message strategies used in online product reviews to further understand characteristics of their content (Berthon, Pitt, \& Campbell, 2008; Dellarocas, 2003; Zhu \& Zhang, 2010). More specifically, the textual content of online product reviews is analyzed in terms of informational and transformational message strategies to explore cultural variations in using different message strategies (Puto \& Wells, 1984). By investigating this topic, this study contributes to the current research stream on digital consumerism in online product reviews by adding the intercultural perspective. Moreover, this study's findings provide practical implications for advertisers who aim to target global consumers in digital markets and strategically use the online product reviews posted by consumers who purchase their products.

\section{Digital Consumerism}

Consumerism has been conceptually defined as a social movement that protects consumers in the marketplace (Jain \& Goel, 2012; Kotler, 1971). Kotler (1971) defined consumerism as "a social movement seeking to augment the rights and power of buyers in relation to sellers" (p. 49). Focusing on consumers' awareness of their rights and power in the marketplace, Jain and Goel (2012) conceptualized consumerism as "a movement concerned with the creation of awareness among consumers regarding their rights and protection of their interests" (2012, p. 256). As an extension of the original concept of consumerism, digital consumerism is a relatively new concept that explains the digitalized marketplace along with the development of digital and social media platforms (Kucuk \& Krishnamurthy, 2007). Digital consumerism is defined as "the development of the paradigms of consumer empowerment and vulnerability in digital markets" (Kucuk, 2016, p. 518). This includes Jain and Goel's (2012) definition of consumerism, and it is modified to reflect digital markets, such as online shopping websites, where consumers have the power to share their opinions. Thus, in the present study, digital consumerism refers to the practice of online consumers exerting their consumer powers in order to be aware of their rights and to facilitate interactions when sharing product information in the digital marketplace.

The emergence of digital markets transformed the ways in which consumers behaved and interacted in online channels (Cummins, Peltier, Schibrowsky, \& Nill, 2014; loanăs \& Stoica, 2014). Nonetheless, online consumers have become more vulnerable due to the issue of misinformation (i.e., unreliable, misleading, and deceptive 
information) in digital markets (Caudill \& Murphy, 2000; Kucuk, 2016). Therefore, the paradigm of consumer empowerment and vulnerability in digital markets (i.e., digital consumerism) has increased the need for market equalization and consumer protection (Kucuk, 2016; Zureik \& Mowshowitz, 2005). Various forms of online consumer powers in digital markets have been identified (Denegri-Knott et al., 2006; Kerr et al., 2012; Kucuk, 2008; Labrecque et al., 2013). For example, Denegri-Knott et al. (2006) suggested that consumer power has three dimensions: sovereignty, cultural power, and discursive power. Similarly, Labrecque et al. (2013) discussed four types of consumer power: demand power, information power, network power, and crowd-based power. These different dimensions of consumer power imply that empowered consumers can interact with other consumers by taking advantage of the technological advances and interactive communication features provided by the Internet.

Kucuk and Krishnamurthy (2007) identified four specific types of online consumer power in the context of online transactions: technologic, economic, social, and legal. Technologic power refers to the flexibility and mobility consumers have in online transactions. Economic power refers to consumers' rights to have access to more purchasing options in the market and to make effective decisions based on available information. Social power is the right to be informed through various online media tools, such as e-commerce or product review websites. Lastly, legal power refers to the consumer's right to safety; it is enhanced through the digitalized environment because consumers can easily obtain information about product safety online (e.g., information about refunds or exchanges and the sellers' credibility). In addition, Kucuk (2008) elaborated upon the synergetic mechanisms among the four sources of power in terms of the consumers' dual roles as a market actor and a citizen. Thus, technologic power and economic power represent the consumers' power as market actors to find better deals and influence their preferences in the marketplace. Social power and legal power represent the consumers' power as citizens, voicing their rights and opinions.

According to the Consumer Empowerment Model (Kucuk, 2009), four types of consumer power in digital markets can be found in online product reviews. In online product reviews, technologic power is expressed by remarking on the convenience of using the Internet for shopping (e.g., "It was easy and fast to buy this product using this online website."). Similarly, economic power is reflected in product reviews that explain the benefits of shopping online to find better quality and more affordable products (e.g., "It has been better to shop online to get this product at a cheaper price."). Social power is expressed by indicating easier communication with other online consumers to make better purchasing decisions (e.g., "It was helpful to see what others thought about this product online before I made the purchase decision."). Lastly, legal power is a component of product reviews in terms of accessibility to information about companies or consumers' privacy concerns (e.g., "Information of the seller posted together with the product made me feel comfortable when I processed the payment to buy this product."). In online product reviews, these four online consumer powers have been viewed as the practice of digital consumerism (Bailey, 2005). In short, online product reviews are one of the outlets where online consumers can protect themselves by interacting with others to make better purchasing decisions, which in turn, enhances their digital consumerism.

\section{Digital Consumerism in Online Product Reviews}

Product reviews on online shopping websites play a significant role in digital markets in that consumers write online reviews to pursue their rights and express their opinions (Li \& Hitt, 2008; Li et al., 2013; Pollach, 2006). This is because consumers might perceive online product reviews written by other consumers as a more helpful source of information than reviews written by experts, such as those who are hired by e-commerce vendors (Li et al., 2013). Previous research that examined the impact of online product reviews has been conducted in a variety of contexts, including the roles of online product reviews in purchasing products (Zhu \& Zhang, 2010), the credibility of online product reviews (Jensen, Averbeck, Zhang, \& Wright, 2013), the review's characteristics and its effects (Hu, Liu, \& Zhang, 2008), and the role of online product reviews in choosing hotels (Barreda \& Bilgihan, 2013; Sidali, Schulze, \& Spiller, 2009).

However, product reviews do not always have positive impacts on purchasing decisions. In fact, product reviews may include bias due to the consumers' personal experiences, which might influence potential consumers' perceptions of the product (Li \& Hitt, 2008). Moreover, depending on the platform where the product reviews were displayed (i.e., personal blogs vs. a brand's website), the reviews have been found to have a different effect on recommending products to others (Lee \& Youn, 2009). Applying online consumer power dimensions to the results 
reported in previous studies, Lee and Youn's (2009) finding can represent the social power of online consumers. In other words, online product reviews can be viewed as a medium to express digital consumerism.

Product review research has extensively examined how product reviews are perceived differently depending on the sources (Jensen et al., 2013; Lee \& Youn, 2009; Li \& Hitt, 2008), and this has a significant impact on the product's reputation as well as the consumers' decision to make other purchases (Siano et al., 2011; Zhu \& Zhang, 2010). Particularly, Siano et al. (2011) proposed that consumer empowerment in online spaces made the reputation of brands in online product reviews more influential given that consumers can construct their opinions and easily share them with others. In digital markets, there are specific patterns to the ways in which consumers construct their opinions in. For example, Pollach (2006) conducted a textual analysis of consumer opinion websites in terms of structure, content, word choice, and a product review's appeal to its audience; they found that online product reviews tend to include reasonable details and follow specific writing conventions (e.g., use of capital letters, questions posed to the audience, hyperlinks, etc.).

Despite ample empirical evidence investigating the role of online product reviews, qualitative methods are rarely used in this line of research. For example, in their thorough review of electronic Word-Of-Mouth (eWOM) literature, King et al. (2014) noted that there was a lack of evidence observed in qualitative approaches. King et al. (2014) recommended that online product reviews should be further investigated to understand consumers' consumption and participation in eWOM and how they process information in online reviews. In an attempt to use qualitative methods to provide more insight and to better understand the content of online product reviews, digital consumerism has been explored in terms of online consumer powers, such as economic power and social power (Pollach, 2006; Siano et al., 2011). Siano et al. (2011) articulated that online consumer empowerment in markets via eWOM would affect online brand reputation; they highlight the significance of monitoring online interactions between consumers and brands. Nonetheless, few studies have investigated the underlying meaning and structure of the content of online product reviews, which could provide valuable insight into the ways in which consumers represent digital consumerism. To address this gap in the literature, the present study asks the following research question:

Research Question 1: How is digital consumerism expressed in online product reviews?

\section{Digital Consumerism and Cultural Differences in Message Strategy}

According to Hofstede (2011), six dimensions can be used to better understand culture: power distance, uncertainty avoidance, individualism/collectivism, masculinity/femininity, long/short-term orientation, and indulgence/restraint. Among these six dimensions, individualism vs. collectivism has been most widely adopted in previous intercultural and international studies (Kashima et al., 1995; Oyserman, Coon, \& Kemmelmeier, 2002; Singelis, 1994). Individualism is a mindset that focuses on individuals, self-fulfillment, and identity based on personal accomplishments. People from an individualistic culture tend to consider themselves to be separated from others and have a high level of self-reliance, maintaining a certain distance from other people (Oyserman et al., 2002). Collectivism is characterized by an interdependent mindset where people value harmony with others and connectedness with members of their group (Singelis, 1994). People from a collectivistic culture tend to see themselves as being integrated into cohesive in-groups (Hofstede, 2011). According to Hall (1989), there are two different communication styles: high-context communication and low-context communication. In high-context communication, most information is either internalized in a specific context or explained using contextual cues; this type of communication style is often found in collectivistic cultures. In contrast, in low-context communication, information is communicated explicitly without contextual cues; this type of communication style is often found in individualistic cultures (Hall, 1989).

The two communication styles introduced by Hall (1989) are expected to lead to differences in expressing digital consumerism in online product reviews by constructing words, phrases, or sentences with or without contextual expressions and sharing the messages with other consumers in digital markets. Based on the theoretical explanations regarding cultural differences in a high-context culture (e.g., a collectivistic culture) and a low-context culture (e.g., an individualistic culture), the strategies adopted to construct messages in online product reviews are expected to differ depending on the communication style used in these two types of cultures (Hall, 1989). In particular, consumers from a collectivistic culture are more likely to construct transformational messages with 
contextual cues, such as emotional expressions; consumers from an individualistic culture are more likely to use informational messages that provide objective information in a more direct way (Cutler, Thomas, \& Rao, 2000; Puto \& Wells, 1984).

In the context of advertising, message strategies also tend to differ by culture (Aaker \& Maheswaran, 1997; Cui, Liu, Yang, \& Wang, 2013; Cutler et al., 2000; Puto \& Wells, 1984). Puto and Wells (1984) identified two types of advertising categorized by its focus on different types of messages: informational advertising and transformational advertising. Informational advertising appeals to consumers' logic or rationality; transformational advertising appeals to consumers' emotions or senses (Puto \& Wells, 1984). Informational messages provide consumers with meaningful information and objective facts (Cutler et al., 2000); transformational messages contain exciting or enjoyable descriptions of the product and attempt to induce emotional responses from consumers (Cutler et al., 2000). Consumers in an individualistic culture, such as the United States (US) are more favorable to advertising that includes informational messages than people in a collectivistic culture, such as South Korea (Aaker \& Maheswaran, 1997). However, people in a collectivistic culture rely more on transformational messages that include emotional and symbolic elements (Cui et al., 2013). Cutler et al. (2000) found that, in the US (an individualistic culture), newspaper, magazine, and television advertisements mainly use informational appeals; in India (a collectivistic culture), advertisements mainly use transformational appeals.

Because product reviews are written by consumers, not by advertisers or companies, they are viewed as consumer-generated ads (Berthon et al., 2008). Dellarocas (2003) stated that online product reviews have become one of the most efficient low-cost advertising channels used to attract consumers. People tend to rely on the opinions that others post online to make purchase decisions, so product reviews have been found to influence consumers' perceptions about products (Jensen et al., 2013; Li et al., 2013). In particular, product reviews that include detailed price or functional information have an informational influence on consumers (Bailey, 2005). For example, the review of a digital camera, including its specifications (e.g., 12 megapixels, $45 \mathrm{~mm}$ lens) and price information (e.g., \$179), would be considered to be an informational product review. In contrast, reviews about the same camera that include emotional (e.g., being a good companion for our trip) or subjective opinions (e.g., a great gift for my mom) would be considered transformational product reviews. By adopting the theoretical framework of informational and transformational message strategies, which previous studies have widely used to examine advertising content (Bailey, 2005; Cui et al., 2013; Cutler et al., 2000), it is also possible to analyze the textual content of online product reviews, a form of user-generated advertisements, within the concepts of informational and transformational message strategies (Dellarocas, 2003).

Kucuk (2002) analyzed consumerism and online consumer powers from a global perspective and observed significant cultural differences between individualistic cultures and collectivistic cultures. Kucuk (2002) found a clear difference in that technologic and legal powers were prevalent in individualistic cultures; consumers from those types of cultures were more likely to value availability and convenience and the security issue of online shopping than consumers from collectivistic cultures. In addition, despite the lack of research on the cross-cultural differences in message strategies used in online product reviews, Hofstede's (2011) and Hall's (1989) theoretical contributions and relevant previous studies (e.g., Puto \& Wells, 1984) provide theoretical and empirical foundations upon which to ask a question, which is: Do the ways in which people express their digital consumerism and construct online product reviews, by using different message strategies (i.e., informational message, transformational message), vary across individualistic and collectivistic cultures? Based on the theoretical backgrounds of digital consumerism and message strategies (e.g., informational, transformational, or both), the present study aims to explore how consumers from different cultures construct their opinions differently in online product reviews as a way to express their digital consumerism. Thus, the following second research question is posed:

Research Question 2: How is digital consumerism expressed differently depending on cultures (i.e., individualistic vs. collectivistic culture) with message strategies in online product reviews? 


\section{Method}

This study conducted a discourse analysis of 400 online product reviews to understand the representation of digital consumerism in the U.S. and South Korea and to compare message strategies used to express digital consumerism. The U.S. was chosen as an individualistic culture with 18 out 100 for the individualism score, and South Korea was chosen as a collectivistic culture with 91 out 100 for the individualism score (Hofstede \& Minkov, 2010). Analyzing keywords, phrases, and propositions used in a text, the discourse analysis uncovers how a text is constructed and what it aims to explain (Dick, 2004). In addition to studying underlying meanings of words and sentences, the discourse analysis is used to identify the coherence of themes. A theme in a discourse analysis is defined as the constituent of a phrase that is used to deliver an intended message (Alyousef, 2016). Themes would provide deeper insight into understanding the content of the text (Van Dijk, 1981).

Despite the limited discourse analysis research in the context of product review research, it is an appropriate approach in that online product reviews consist of words and phrases, which includes connotations and denotations regarding consumers' opinions about the product. To understand in-depth and implicit meanings or themes of online product reviews and relevant online consumer powers expressed across the two cultures, the discourse analysis is considered a unique and appropriate research method to use in this study. As this study aims to investigate how digital consumerism is constructed in online product reviews and how it is different between the U.S. and South Korea, themes are identified based on the online consumer powers. Such process would help to understand the grounded message of the online product reviews in terms of digital consumerism. In addition, informational and transformational message strategies employed in the online product reviews were investigated and compared between the U.S. and South Korea.

\section{Data Collection}

The data were collected from two different online shopping websites: Amazon.com from the U.S., which represents the individualistic culture and Gmarket.co.kr from South Korea, which represents the collectivistic culture. The Amazon website was selected because it is one of the biggest online shopping websites that people in the U.S. use. In addition, the Gmarket website is one of the biggest online shopping websites in South Korea, which can be considered as a comparable website to Amazon. In addition, both websites share several similarities in its functions. For instance, both websites provide keywords search, customer ratings, customer reviews, comparing with similar items, customer questions and answers, and specific shipping options that consumers can select. Consumers are able to shop various products of their interest by using those functions provided in both websites. Consumers are allowed to write their opinions about the product or purchase under the product specifications, which are open to the public. It is required to log in to write a customer review in both websites.

To minimize the effects of product characteristics, a laundry detergent brand was chosen as the target product category because household items are not polarized on either side of product involvement (Vaughn, 1980; Weinberger \& Spotts, 1989). Ultra Downy April Fresh Liquid Fabric Softener was chosen the target product, as it was sold on both websites, and it was one of the most widely sold fabric softeners. In terms of prices, the target product, Ultra Downy April Fresh Liquid Fabric Softener, was not sold as the cheapest fabric softener, nor the most expensive fabric softener among the other kinds of fabric softener in both countries. After sorting all of the reviews by the most recent dates posted on September 10, 2017 in both websites, the first 200 product reviews of the product in each website were captured and saved for the coding process. The unit of analysis was a product review written by a consumer.

\section{Coding Themes}

Digital consumerism. Each online consumer power was identified as a theme of digital consumerism found in the online product reviews based on the previous studies (Kucuk, 2002, 2009). The technologic power was identified with words or phrases in online product reviews mentioning the ease or benefits of purchase using the Internet or online websites (an example from data: "Just by some clicks, I could easily get the product from this website."). The economic power was identified with words or phrases mentioning the price and value of the product or purchasing-related comments (an example from data: "Using coupons from this website was helpful."). The social power was identified with words or phrases mentioning communication with other people who were 
looking for the same or similar product (an example from data: "If you are looking for a good fabric softener, this product should be your choice."). The legal power was identified with words or phrases mentioning consumers' ability to have access to information about companies or sellers, exchange or return policies, or any privacy concerns related to the purchase (an example from data: "I contacted the seller to exchange this product into new one because it came with leakage.").

Message strategy. This study focused on two message strategies: informational and transformational messages (Puto \& Wells, 1984). Informational message refers to messages that appeal to consumers' rationality by providing objective facts, whereas transformational message refers to messages that appeal to consumers' senses by including emotional experiences and descriptions related to products (Cutler et al., 2000; Puto \& Wells, 1984). Each message strategy was identified as a theme of message strategy found in online product reviews. The informational message was defined as words or phrases containing the objective information of the product or purchase, such as pricing, shipping, or functional information (an example from data: "The scent of this fabric softener lasted for a week."). The transformational message was characterized by words or phrases explaining emotional or subjective opinions, such as personal experiences or stories related to the purchase or usage of the product (an example from data: "My mom used this fabric softener for several years and all of our family members are satisfied with this.").

\section{Coding Procedure}

After raw data from each online shopping website were collected, a codebook was created for initial categorization of words in product reviews. The specific themes of interest include: Kucuk's (2009) four types of online consumer power (i.e., technologic, economic, social, and legal power) and Puto and Wells' (1984) two message strategies (i.e., informational and transformational message). Kucuk (2009) described each type of online consumer power by its characteristics, but did not provide specific dimensions or measurements of each online consumer power. Thus, four online consumer powers were coded only when productive reviews explicitly included Kucuk's (2009) descriptions and matched with examples provided in the codebook. Two message strategies by Puto and Wells (1984) were also described with definitions and examples in the codebook. The codebook was created in both languages, English and Korean, as four coders (i.e., two American coders and two Korean coders) conducted the first round of coding. Two native English-speaking coders coded 200 product reviews from Amazon.com. Each coder was given 100 product reviews and the codebook. The other two native Korean coders who are fluent both in English and Korean coded 200 product reviews from Gmarket.co.kr following the same process. Coder training was conducted with 10 percent of the total samples given to each coder. Through coder training, the codebook was revised to clarify coding instructions. Final inter-coder reliability for the categorization of words by variables was $79.1 \%$ (American coders) and $80.8 \%$ (Korean coders), which was found to be acceptable.

After several coder training sessions, coders read through all the posts copied and pasted in the coding sheet. Following the codebook, each coder categorized words and phrases into each category of themes. After four coders completed the first coding, the researcher conducted the second round of coding to identify and compare the themes with what coders identified. During this process, the themes of online product reviews obtained from each website were identified based on four coders' categorization of themes. Identified themes were then compared between the U.S. and South Korea.

\section{Results}

\section{RQ1: How is Digital Consumerism Expressed in Online Product Reviews?}

Four types of online consumer powers were expressed in online product reviews collected for this study. First of all, technologic power was expressed in a way that consumers left comments about the benefits of using online shopping websites to buy the product over purchasing it in offline stores. For instance, technologic power was implied in the collected comments by using phrases such as "save a trip to the store," "easier than lugging things from the store," and "delivered right on my porch." Below are some example comments implying technologic power, which pointed out the convenience of buying the product through the Internet in general or online shopping websites: 
U.S.: "For those that do not have easy access to a store, this is a great option!"; "Delivered on time!"; "I tried the Amazon Pantry and was impressed. Saved me a trip to the store."

South Korea: "Just by some clicks, I could easily get the product from this website"; "Arrived on time and as described"; "Shipping was very fast."

Second, economic power was shown in comments mentioning the price benefits of online purchase and value of the product. Specifically, consumers shared the information of on-going sales promotion or coupons applicable to the product, or they compared the online purchase with offline purchase by evaluating economic benefits. Below are some example comments implying economic power, which compared the online purchase with offline purchase at supermarkets and evaluated the economic benefits of purchasing the product online:

U.S.: "Buying this product here is cheaper than buying from other supermarkets"; "Since it needs to be diluted with water for my high efficiency washer, this amount last for months."

South Korea: "I'm very satisfied with this purchase because the price was cheaper than supermarkets"; "I got it at cheaper price because I had a coupon"; "It's cheaper than offline purchase but it's not way cheaper than I expected."

Third, social power was expressed in the comments highlighting the benefits of interacting with other consumers by sharing positive or negative feedback of the product. For example, phrases such as "highly recommend" and "bought this product after reading the reviews" were commonly found. Below are some example comments implying social power:

U.S.: "Excellent product and totally recommend!"; "If you like cleaning out your washing machine every cycle, use this stuff. Don't believe me? Go to the manufacturer's website. This product has 1.2 out of 5 rating with 1200 reviews because it clogs machines."

South Korea: "I've had another product at my place but got this product from reading the positive reviews at this website"; "If you like sweet or floral scent like me, I recommend this product."

A majority of the comments implying social power indicated that consumers recommended to other consumers who were looking for similar products and shared their intention to buy the product again in the future. Some comments also provided product-related information from other review websites.

Lastly, legal power indicating access to seller information or policies (e.g., credibility of seller, refund, or exchange) was observed in a few comments, but not as much as the other three types of powers. Phrases from the collected data, such as "use this seller again" and "need to contact seller for exchange" implied the legal power of online consumers. Below are some example comments implying legal power:

\section{U.S.: "Do I have to resend this product to the seller to exchange this leaking product?"; "Will use this seller} again."

South Korea: "I contacted the seller to exchange this product into new one because it came with leakage"; "I have used this seller for other products as well and it has been always reliable."

Taken together, each power type revealed in the online product reviews has been found to indicate different aspects of benefits that online purchases in e-commerce websites offer, such as convenience of online shopping, exclusive time-limited deals for online shopping. For instance, technologic power of online consumers pointed out technological advantages of online shopping in that shopping through e-commerce websites allowed them to get products in easier and faster way in comparison to offline purchases. In online product reviews, the results indicated that consumers acknowledge the convenience of using e-commerce websites and explicitly indicate its technological benefits in their reviews to share the advantages with other consumers. Economic power in the online product reviews highlighted the economic benefits that online shopping provides (e.g., coupons, discounts) as well as value of the products (e.g., cost-effectiveness of products). Specifically, consumers who are aware of 
other price options available for related purchases (e.g., coupons) were found to share the information with other consumers through the online product reviews. Comparison of prices and product values with similar products from competitor brands was also found as a form of expressing economic power of consumers in online product reviews. Social power of online consumers was mostly related to consumers' intention to spread the words to other consumers by sharing their personal experience with the past purchases. By expressing social power in the online product reviews, consumers either provide positive recommendations or complaints about the products based on their experiences. Lastly, legal power was often associated with exchanges or refunds of products and communication with the seller. A few online product reviews reflected legal power of online consumers as a form of requesting changes regarding their purchases or mentioning credibility and responsibility of the seller.

In terms of frequency (see Table 1), economic power was observed the most in both countries, followed by social power and technologic power. Although there were quite a few reviews that included other information, such as detailed explanations about functionality of products and overall satisfaction with the purchases, the main topic discussed in online product reviews from both countries was pricing information related to coupons and discounts, which might directly affect their purchase decision (i.e., economic power). In addition, consumers not only read the product information provided by sellers, but also actively seek additional information about the products or purchases from online product reviews written by other consumers who previously bought the same products (i.e., social power). Meanwhile, there were several online product reviews that revealed more than one type of power in the comments. For example, in the U.S. online product reviews, 11 reviews revealed technologic power and economic power together in each product review, highlighting the convenience of using e-commerce websites (i.e., technologic power) and economic advantages of online shopping (i.e., economic power). In Korean online product reviews, 7 reviews included economic power and social power together in one product review. These results imply that some Korean consumers write reviews to give out the pricing information with discounts or coupons to other consumers who are looking for similar products.

Table 1. Frequency of Coded Variables.

\begin{tabular}{|c|c|c|}
\hline & United States & South Korea \\
\hline \multicolumn{3}{|c|}{ Online Consumer Powers } \\
\hline Technologic Power & 31 & 31 \\
\hline Economic Power & 37 & 51 \\
\hline Social Power & 28 & 33 \\
\hline Legal Power & 9 & 4 \\
\hline Other & 95 & 81 \\
\hline Total & 200 & 200 \\
\hline \multicolumn{3}{|l|}{ Message Strategies } \\
\hline Informational & 29 & 35 \\
\hline Transformational & 148 & 102 \\
\hline Other & 23 & 63 \\
\hline Total & 200 & 200 \\
\hline
\end{tabular}

\section{RQ2: How is Digital Consumerism Expressed Differently Depending on Cultures (i.e., Individualistic vs. Collectivistic Culture) with Message Strategies in Online Product Reviews?}

The frequency of each online consumer power observed in two countries suggests cultural differences in the representation of digital consumerism (see Table 1). That is, among the four powers of digital consumerism, the most frequently observed powers were different between individualistic and collectivistic cultures. Consistent with the previous finding from Kucuk (2002), economic, technologic, and social power were observed as frequent 
themes in online product reviews from the U.S. (i.e., individualistic culture), followed by legal power. On the other hand, economic power was found to be the most frequent theme in online product reviews from South Korea (i.e., collectivistic culture), followed by social and technologic power. Specifically, a majority of online product reviews written by consumers on Amazon contained price information (i.e., economic power), the convenience of using the online shopping website (i.e., technologic power), and sharing opinions with others about the product (i.e., social power). However, Korean consumers constructed online product reviews with comments mostly centered on the price information of the product (i.e., economic power), and some comments included the benefits of communicating with other consumers (i.e., social power) and the convenience of purchasing the product online (i.e., technologic power).Transformational words and phrases were observed in the comments to express social power. Transformational messages were used to communicate with other consumers about their emotional or subjective opinions. Below are some example comments showing transformational messages to express social power:

Social power: "I have tried others but always seem to go back to Downy. You guys should try it"; "People say there's the scent of our family whenever I use this product. I'm very happy with that"; "My cousins also bought this product after I told them I liked the scent of this fabric softener."

Both message strategies were found in the individualistic and collectivistic cultures. In terms of frequency, transformational messages were more frequently used as a dominant message strategy in both cultures (see Table 1). The results showed little cultural difference in a dominant message strategy used to construct digital consumerism in online product reviews. However, in Korean data, there were a large number of comments using both informational and transformational message strategies, which were included in the "other" category. In addition, subsequent analyses on the expression of four online consumer powers by message strategies revealed that informational and transformational message strategies were used differently in the two cultures to express each type of online consumer powers (see Table 2). When it comes to expressing technologic power, informational message $(n=13)$ and transformational messages $(n=13)$ were both evenly used in the U.S. reviews, whereas informational message ( $n=16)$ was more frequently used than transformational message $(n=4)$ in Korean reviews to express technologic power (an example from data: "Arrived on time and as described."). Economic power in the U.S. reviews was expressed more with transformational message $(n=23)$ (an example from data: "Still the best fabric softener on the market in a large, economical size. Pleasant scent and does the job.", whereas informational message ( $n=18$ ) was more frequently used in Korean reviews (an example from data: "Buying this product here is cheaper than buying from other supermarkets."). In other words, Korean consumers were more likely to provide objective information when expressing their technologic and economic powers as consumers, whereas American consumers tend to provide more personal and emotional experiences when expressing economic power.

Table 2. Expression of Online Consumer Powers by Message Strategies.

\begin{tabular}{lcc}
\hline & United States & South Korea \\
\hline Informational Message & 13 & 16 \\
Technologic Power & 5 & 18 \\
Economic Power & 2 & 1 \\
Social Power & 2 & 0 \\
Legal Power & & \\
Transformational Message & 13 & 4 \\
Technologic Power & 23 & 11 \\
Economic Power & 25 & 12 \\
Social Power & 7 & 4 \\
Legal Power & 110 & 134 \\
Other & 200 & 200 \\
Total & & 4 \\
\hline Note: The & 25 . & \\
\hline
\end{tabular}

Note: The "Other" category in message strategies includes product reviews that were not categorized into any of the two message strategies or can be categorized as both informational and transformational message strategies. 
In terms of social power and legal power, both cultures used transformational message more frequently than informational message (an example from data: "I have tried others but always seem to go back to Downy. You guys should try it.") (see Table 2). This means that both American and Korean consumers share more personal experiences and emotions associated with the purchase when interacting with other consumers (i.e., social power) as well as dealing with issues with the seller (i.e., legal power). Although overall message strategy usage in the online product reviews was more toward transformational message in both cultures, different patterns between the U.S. and Korean online product reviews were observed when comparing the expressions of different types of online consumer powers, respectively.

\section{Discussion}

This study aimed to investigate the representation of digital consumerism in online product reviews and to further explore the cultural differences in the construction of digital consumerism based on two message strategies. The discourse analysis identified six themes related to constructing digital consumerism in online product reviews: four online consumer powers (technologic, economic, social, and legal) and two message strategies (informational and transformational).

The results of this study demonstrate that there are cultural differences in the representation of digital consumerism. More specifically, consumers from an individualistic culture tend to focus more on economic power, technologic power, and social power, and consumers from a collectivistic culture tend to primarily focus on economic power, followed by social and technologic power. These findings on cultural differences were in line with the previous analyses of consumerism and online consumer powers reported by Kucuk (2002). In terms of the message strategies used in online product reviews, transformational messages were predominantly used in both types of cultures. It is important to note that quite a few of the comments from the South Korean data of online product reviews use both types of message strategies, whereas only a small fraction of the comments in the US data included both message strategies. This could imply that the dimension of informational vs. transformational message strategies, which was developed by Western researchers, might not fit well with the representation of digital consumerism in a collectivistic culture. Thus, using message strategies other than informational or transformational message strategies could provide more insight into digital consumerism in a collectivistic culture.

The present study's finding suggests that online product reviews enabled online consumers to express digital consumerism to protect their rights as consumers in digital markets. Consumers from the individualistic culture tended to express three types of consumer power, comparably, in online product reviews: economic power, technologic power, and social power. This implies that, in individualistic cultures, online product reviews might facilitate the use of online shopping websites based on the benefits associated with price information, technological availability and convenience, and their ability to communicate with other consumers. However, consumers from the collectivistic culture seemed to care more about the economic advantages they could gain from online shopping than the other three consumer powers (technologic, social, and legal). In both types of cultures, social power was often expressed. This indicates that consumers from both individualistic and collectivistic cultures actively utilize online product reviews as a tool to communicate with other consumers. In addition, legal power was rarely found in either of the two types of cultures examined in this study.

Because informational messages are mainly used to express technologic power, economic power, and legal power, it seems to imply that consumers need objective information about a product when it comes to the purchasing platform, price, or value of the product and the possible transaction issues that might occur in the online shopping process. In contrast, transformational messages were mainly used to express social power. This implies that communicating with other consumers is mainly done by sharing emotional experiences and personal stories instead of sharing objective information. However, this study did not clearly identify any cultural differences in the message strategies used to represent digital consumerism, which is not consistent with the findings reported in previous research (Aaker \& Maheswaran, 1997; Cui et al., 2013; Cutler et al., 2000; Puto \& Wells, 1984). These inconsistent findings might be related to the communication platform. That is, online shopping websites operate under the Internet culture, which is different from face-to-face communication, which was primarily the context in which previous studies found significant cultural differences in the representation of consumerism (Preece \& Maloney-Krichmar, 2005). Because online consumers communicate with others within an 
online community, the ways in which messages are constructed in online platforms might be different from how they are constructed in an offline environment.

The present study's findings have several theoretical and practical implications. Although several previous studies discussed the concept of digital consumerism and online consumer powers, most focused on the conceptualization level or aimed to clarify the characteristics of online consumers and digital markets (Kucuk, 2009, 2016; Kucuk \& Krishnamurthy, 2007). Thus, few studies have attempted to investigate the actual practices of digital consumerism. The present study contributes to the research stream of consumerism in that it examined the representation of digital consumerism and online consumer powers in existing online product reviews. Given that online product reviews can be as persuasive as other advertising messages (Goes, Lin, \& Au Yeung, 2014; Tirunillai \& Tellis, 2012), it is important to understand the underlying meaning of online product reviews to protect consumer rights in digital markets. To the best of our knowledge, this study is the first to incorporate discourse analysis into product review research and to investigate the underlying meaning of the content of product reviews. Furthermore, by looking at the cultural differences in the representation of digital consumerism in online product reviews, this study also investigated digital consumerism from an intercultural perspective.

Online product reviews are becoming a powerful advertising tool, worldwide (Berthon et al., 2008; Dellarocas, 2003), so the findings of this study provide practical implications for advertisers seeking to target international consumers. By monitoring online product reviews, advertisers can understand what types of online consumer powers are being discussed among customers. Once advertisers identify the prominent online consumer powers observed in the online product reviews, they can develop and launch advertising campaigns that match the most prominent consumer powers so that their target consumers will have a positive perception that the company is protecting their consumer powers. The cultural difference observed in this study also implies that it may be important for companies to identify the different prominent online consumer powers found in different cultures to better plan for future advertising campaigns and develop strategies that show respect for consumers' rights. This will enable advertisers to empower consumers, which in turn, will help maintain the power balance between consumers and companies in the digital markets.

\section{Limitations and Suggestions for Future Research}

There are some limitations in this study. First, one specific online shopping website from each culture (i.e., individualistic and collectivistic culture) was selected for the analyses. Although both websites met certain criteria to fit the purpose of this study, a number of online shopping websites, which has special features (e.g., bidding or auction-based, online shopping websites only specialized in certain product category), exist. The characteristics of online shopping websites may influence the representation of digital consumerism. In terms of message strategies, this study included informational and transformational message strategies only. Future research is recommended to incorporate other message strategies to better understand message characteristics. Although the findings of this study revealed the differences of representing digital consumerism and online consumer powers with two different message strategies between the two countries, U.S. and South Korea, further efforts are needed to support the claim that such differences are due to the cultural differences in digital consumerism by providing more clear evidence. This study adopted Hofstede's (2011) individualism and collectivism to explore macro-level cultural differences between the two countries, however, future research is also recommended to incorporate individual differences over national characteristics in this context to overcome the limitations that Hofstede's (2011) macro-level cultural differences might have in order to explain individual consumers' perspective. In addition, the difference between product involvement (i.e., high vs. low involvement product) was not considered as a possible significant factor in this study. Product involvement might have an effect on how people express and construct digital consumerism in online product reviews. Taken together, future researchers are encouraged to investigate various types of online shopping websites and take product involvement into consideration. 


\section{References}

Aaker, J. L., \& Maheswaran, D. (1997). The effect of cultural orientation on persuasion. Journal of Consumer Research, 24, 315-328. https://doi.org/10.1086/209513

Alyousef, H. S. (2016). A multimodal discourse analysis of international postgraduate business students' finance texts: An investigation of theme and information value. Social Semiotics, 26, 486-504.

https://doi.org/10.1080/10350330.2015.1124518

Bailey, A. A. (2005). Consumer awareness and use of product review websites. Journal of Interactive Advertising, 6(1), 68-81. https://doi.org/10.1080/15252019.2005.10722109

Barreda, A., \& Bilgihan, A. (2013). An analysis of user-generated content for hotel experiences. Journal of Hospitality and Tourism Technology, 4, 263-280. https://doi.org/10.1108/JHTT-01-2013-0001

Berthon, P., Pitt, L., \& Campbell, C. (2008). Ad lib: When customers create the ad. California Management Review, 50(4), 6-30. https://doi.org/10.2307/41166454

Caudill, E. M., \& Murphy, P. E. (2000). Consumer online privacy: Legal and ethical issues. Journal of Public Policy \& Marketing, 19, 7-19. https://doi.org/10.1509/jppm.19.1.7.16951

Cui, G., Liu, H., Yang, X., \& Wang, H. (2013). Culture, cognitive style and consumer response to informational vs. transformational advertising among East Asians: Evidence from the PRC. Asia Pacific Business Review, 19, 16-31. https://doi.org/10.1080/13602381.2011.626967

Cummins, S., Peltier, J. W., Schibrowsky, J. A., \& Nill, A. (2014). Consumer behavior in the online context. Journal of Research in Interactive Marketing, 8, 169-202. https://doi.org/10.1108/JRIM-04-2013-0019

Cutler, B. D., Thomas, E. G., \& Rao, S. R. (2000). Informational/transformational advertising: Differences in usage across media types, product categories, and national cultures. Journal of International Consumer Marketing, 12(3), 69-83. https://doi.org/10.1300/J046v12n03_05

Dellarocas, C. (2003). The digitization of word of mouth: Promise and challenges of online feedback mechanisms. Management Science, 49, 1407-1424. https://doi.org/10.1287/mnsc.49.10.1407.17308

Denegri-Knott, J., Zwick, D., \& Schroeder, J. E. (2006). Mapping consumer power: An integrative framework for marketing and consumer research. European Journal of Marketing, 40, 950-971.

https://doi.org/10.1108/03090560610680952

Dick, P. (2004). Discourse analysis. In C. Cassell \& G. Symon (Eds.), Essential Guide to Qualitative Methods in Organizational Research (pp. 203-213). London, UK: Sage Publications Ltd.

http://doi.org/10.4135/9781446280119.n17

Donoghue, S., Van Oordt, C., \& Strydom, N. (2016). Consumers' subjective and objective consumerism knowledge and subsequent complaint behaviour concerning consumer electronics: A South African perspective. International Journal of Consumer Studies, 40, 385-399. https://doi.org/10.1111/ijcs.12259

Goes, P. B., Lin, M., \& Au Yeung, C. M. (2014). “Popularity effect” in user-generated content: Evidence from online product reviews. Information Systems Research, 25, 222-238. https://doi.org/10.1287/isre.2013.0512

Hall, E. T. (1989). Beyond culture. New York, NY, US: Anchor Books.

Hofstede, G. (2011). Dimensionalizing cultures: The Hofstede model in context. Online Readings in Psychology and Culture, 2(1), article 8. https://doi.org/10.9707/2307-0919.1014 
Hofstede, G., \& Minkov, M. (2010). Long-versus short-term orientation: New perspectives. Asia Pacific Business Review, 16, 493-504. https://doi.org/10.1080/13602381003637609

Hu, N., Liu, L., \& Zhang, J. J. (2008). Do online reviews affect product sales? The role of reviewer characteristics and temporal effects. Information Technology and Management, 9, 201-214. https://doi.org/10.1007/s10799-008$0041-2$

International Post Corporation. (2016). IPC cross-border e-commerce shopper survey 2016. Available from https://www.ipc.be/en/knowledge-centre/e-commerce/cross-border-e-commerce-shopper-survey

International Post Corporation. (2017). State of e-commerce: Global outlook 2016-21. Available from https://www.ipc.be/en/knowledge-centre/e-commerce/Articles/global-ecommerce-figures-2017

Ioanăs, E., \& Stoica, I. (2014). Social media and its impact on consumers behavior. International Journal of Economic Practices and Theories, 4, 295-303.

Jain, S. K., \& Goel, P. (2012). Consumer attitudes towards business firms' marketing philosophy, consumerism and government regulations in India: A cross-sectional analysis. Vision: The Journal of Business Perspective, 16, 253271. https://doi.org/10.1177/0972262912460184

Jensen, M. L., Averbeck, J. M., Zhang, Z., \& Wright, K. B. (2013). Credibility of anonymous online product reviews: A language expectancy perspective. Journal of Management Information Systems, 30(1), 293-324.

https://doi.org/10.2753/MIS0742-1222300109

Kashima, Y., Yamaguchi, S., Kim, U., Choi, S. C., Gelfand, M. J., \& Yuki, M. (1995). Culture, gender, and self: A perspective from individualism-collectivism research. Journal of Personality and Social Psychology, 69, 925-937. https://doi.org/10.1037/0022-3514.69.5.925

Kerr, G., Mortimer, K., Dickinson, S., \& Waller, D. S. (2012). Buy, boycott or blog: Exploring online consumer power to share, discuss and distribute controversial advertising messages. European Journal of Marketing, 46, 387-405. https://doi.org/10.1108/03090561211202521

King, R. A., Racherla, P., \& Bush, V. D. (2014). What we know and don't know about online word-of-mouth: A review and synthesis of the literature. Journal of Interactive Marketing, 28, 167-183.

https://doi.org/10.1016/j.intmar.2014.02.001

Kotler, P. (1971). What consumerism means for marketers. Harvard Business Review, 50(3), 48-57.

Kucuk, S. U. (2002). The changing consumerism with the internet: a global perspective. Journal of Euromarketing, 12(1), 41-61. https://doi.org/10.1300/J037v12n01_04

Kucuk, S. U. (2008). Consumer exit, voice, and 'power' on the Internet. Journal of Research for Consumers, 15, 1-13. Retrieved from http://jrconsumers.com/Academic_Articles/issue_15/

Kucuk, S. U. (2009). Consumer empowerment model: From unspeakable to undeniable. Direct Marketing: An International Journal, 3, 327-342. https://doi.org/10.1108/17505930911000892

Kucuk, S. U. (2012). Can consumer power lead to market equalization on the internet? Journal of Research for Consumers, 21, 1-25. Retrieved from http://jrconsumers.com/Academic_Articles/issue_21/

Kucuk, S. U. (2016). Consumerism in the digital age. Journal of Consumer Affairs, 50, 515-538.

https://doi.org/10.1111/joca.12101

Kucuk, S. U., \& Krishnamurthy, S. (2007). An analysis of consumer power on the Internet. Technovation, 27, 47-56. https://doi.org/10.1016/j.technovation.2006.05.002 
Labrecque, L. I., vor dem Esche, J., Mathwick, C., Novak, T. P., \& Hofacker, C. F. (2013). Consumer power: Evolution in the digital age. Journal of Interactive Marketing, 27, 257-269. https://doi.org/10.1016/j.intmar.2013.09.002

Lee, M., \& Youn, S. (2009). Electronic word of mouth (eWOM): How eWOM platforms influence consumer product judgement. International Journal of Advertising, 28, 473-499. https://doi.org/10.2501/S0265048709200709

Li, M., Huang, L., Tan, C. H., \& Wei, K. K. (2013). Helpfulness of online product reviews as seen by consumers: Source and content features. International Journal of Electronic Commerce, 17(4), 101-136.

https://doi.org/10.2753/JEC1086-4415170404

Li, X., \& Hitt, L. M. (2008). Self-selection and information role of online product reviews. Information Systems Research, 19, 456-474. https://doi.org/10.1287/isre.1070.0154

Oyserman, D., Coon, H. M., \& Kemmelmeier, M. (2002). Rethinking individualism and collectivism: Evaluation of theoretical assumptions and meta-analyses. Psychological Bulletin, 128, 3-72. https://doi.org/10.1037/00332909.128.1.3

Pollach, I. (2006). Electronic word of mouth: A genre analysis of product reviews on consumer opinion web sites. In Proceedings of the 39th Annual Hawaii International Conference on System Sciences (HICSS'06) (Vol. 3, pp. 51c-51c). IEEE. https://doi.org/10.1109/HICSS.2006.146

Preece, J., \& Maloney-Krichmar, D. (2005). Online communities: Design, theory, and practice. Journal of ComputerMediated Communication, 10(4), JCMC10410. https://doi.org/10.1111/j.1083-6101.2005.tb00264.x

Puto, C. P., \& Wells, W. D. (1984). Informational and transformational advertising: The differential effects of time. Advances in Consumer Research, 11, 638-643.

Shepard, G. (2017). Global social influencer marketing at a glance: Top five emerging markets. Adweek. Retrieved from http://www.adweek.com/digital/greg-shepard-pepperjam-guest-post-global-social-influencer-marketingtop-five-emerging-markets

Siano, A., Vollero, A., \& Palazzo, M. (2011). Exploring the role of online consumer empowerment in reputation building: Research questions and hypotheses. Journal of Brand Management, 19, 57-71.

https://doi.org/10.1057/bm.2011.23

Sidali, K. L., Schulze, H., \& Spiller, A. (2009). The impact of online reviews on the choice of holiday accommodations. In W. Höpken, U. Gretzel, \& R. Law (Eds.), Information and Communication Technologies in Tourism 2009 (pp. 87-98). Vienna: Springer. https://doi.org/10.1007/978-3-211-93971-0_8

Singelis, T. M. (1994). The measurement of independent and interdependent self-construals. Personality and Social Psychology Bulletin, 20, 580-591. https://doi.org/10.1177/0146167294205014

Tirunillai, S., \& Tellis, G. J. (2012). Does chatter really matter? Dynamics of user-generated content and stock performance. Marketing Science, 31, 198-215. https://doi.org/10.1287/mksc.1110.0682

Van Dijk, T. A. (1981). Discourse studies and education. Applied Linguistics, 2(1), 1-26. Vaughn, R. (1980). How advertising works: A planning model. Journal of Advertising Research, 20(5), 27-33.

Weinberger, M. G., \& Spotts, H. E. (1989). Humor in US versus UK TV commercials: A comparison. Journal of Advertising, 18(2), 39-44. https://doi.org/10.1080/00913367.1989.10673150

Zhu, F., \& Zhang, X. (2010). Impact of online consumer reviews on sales: The moderating role of product and consumer characteristics. Journal of Marketing, 74(2), 133-148. https://doi.org/10.1509/jm.74.2.133 
Zureik, E., \& Mowshowitz, A. (2005). Consumer power in the digital society. Communications of the ACM, 48(10), 46-51. https://doi.org/10.1145/1089107.1089136

\title{
Correspondence to:
}

Joonghwa Lee

Department of Communication

University of North Dakota

Columbia Hall, Room 2370

501 N Columbia Rd. Stop 7169

Grand Forks, ND 58202, USA

Email: joonghwa.lee(at)und.edu

Editorial record: First submission received on October 29, 2018. Revisions received on February 14, 2019, April 18, 2019, and May 5, 2019. Accepted for publication on May 9, 2019.

The article is part of the Special Issue "Digital Advertising and Consumer Empowerment" guest edited by Liselot Hudders (Ghent University, Ghent, Belgium), Karolien Poels (University of Antwerp, Antwerp, Belgium), and Eva van Reijmersdal (University of Amsterdam, Amsterdam, The Netherlands).

\begin{abstract}
About Authors
Haseon Park (M.A., University of North Dakota) is a doctoral student in the Department of Communication at the University of North Dakota. Her research interests include new media and interactive advertising and mobile advertising. Her recent research is specifically related to the consumer responses in online and mobile interaction between consumers and brands. Her research has been recognized in national conferences, such as American Academy of Advertising and Association for Education in Journalism and Mass Communication.

Joonghwa Lee (Ph.D., University of Missouri-Columbia) is an Assistant Professor in the Department of Communication at the University of North Dakota. His research interests lie in interactive and non-traditional advertising as well as consumer behaviors. His research has been recognized in peer-reviewed journals, such as International Journal of Advertising, American Behavioral Scientist, Journal of Marketing Communications, New Media and Society, and Journal of Interactive Advertising.
\end{abstract}

